\title{
An integrated approach for probing the structure and mechanical properties of diatoms: Toward engineered nanotemplates Miguel Diaz Moreno ${ }^{1}$, Kaka Ma $^{2}$, Julie Schoenung ${ }^{2}$, and Lilian P. Dávila ${ }^{1, *}$ \\ ${ }^{1}$ Materials Science and Engineering, School of Engineering University of California Merced, 5200 N. Lake Road, Merced, CA 95343, USA \\ ${ }^{2}$ Department of Chemical Engineering and Materials Science, College of Engineering University of California Davis, One Shields Avenue, Davis, CA 95616, USA \\ * Corresponding author: ldavila@ucmerced.edu Tel.: +1 209228 4707; fax: +1 2092284047
}

\section{ABSTRACT}

The wide variety of diatom frustule shapes and intricate architectures provide viable prototypes to guide the design and fabrication of nanodevices and nanostructured materials for applications ranging from sensors to nanotemplates. In this study, a combined experimental-simulation method was developed to probe the porous structure and mechanical behavior of two distinct marine diatom species, Coscinodiscus sp. (centric) and Synedra sp. (pennate), through ambient nanoindentation and finite element method analysis. These diatom frustule dimensions differed largely depending on diatom species with pore diameters $d$ ranging from 0.3-3.0 $\mu \mathrm{m}$. Young's modulus $E$ and hardness $H$ measurements of the diatom frustules were obtained via nanoindentation experiments. These values varied depending on diatom species ( $E$ from 1.1-10.6 GPa, $H$ from 0.10-1.03 GPa for the Coscinodiscus sp.; and $E$ from 13.7-18.6 GPa, $H$ from 0.851.41 GPa for the Synedra sp.). Additionally, the mechanical response of diatom structures to uniform compression was examined. Predictive simulations were performed on the aforementioned diatom frustules, as well as another diatom structure (pennate F. kerguelensis), to correlate the mechanical response with specific morphology variables (e.g., pore or slit sizes). Results from calculated von Mises stress and displacement distributions unveil unique information on the effect that uniform loads have on these frustules, which can aid the design of tailored nanotemplates. A correlation between mechanical properties and porosity was established for selected frustules, and reported for the first time in this study. 
Keywords: diatoms; nanoindentation; mechanical properties; simulation; bio-inspired materials.

\section{INTRODUCTION}

Five grand challenges to science have been reported [1], which unveiled the need to understand, control, design and synthesize new materials with tailored properties via nanoscale manipulation. In particular, investigations that combine experiments and simulations have been recognized as a more efficient approach for addressing societal challenges, such as the need for advanced materials and nanodevice development [2].

Biomaterials research is an effective path for materials innovation, as it can help adapt the designs of nature to device fabrication methods [1]. Particularly, diatoms investigation can offer insights into advanced material structures, the fabrication of human-made devices, and contribute toward achieving customized properties for novel nanodevices. Although current nanofabrication methods are generally sophisticated, there are still challenges to overcome such as reproducibility, reliability and scalability. In an effort to resolve these challenges, researchers have been focusing on biological organisms as effective prototypes from which to gain valuable insights. Studies of the properties of biosilica structures [3] (e.g., hexactinellid sponges and diatoms) suggest that further investigation of these biomaterials can provide a meaningful contribution toward the realization of tailored properties for novel devices. Such biomaterials are ideal replicas for new materials to be used in realistic conditions (e.g., in water), via controlled hierarchical structures. In this regard, computational investigations can uniquely explore regimes and conditions not fully accessible experimentally, and identify new materials inspired by the diatoms' structure-properties traits, in an efficient and cost-effective manner. Robust experimental and simulation studies together can advance current knowledge further and potentially faster, by taking advantage of the best aspects of both approaches. 
Porous biostructures represent an example of what nanotechnology can ultimately achieve, as they largely exceed the resolution of human-made nanotechnologies [1,4], and innovative research is being actively pursued in this area $[1,3]$. Small marine microorganisms such as diatoms and some sea sponges grow under various temperature and environmental conditions. Silica glass is hence largely used as a building material in these biostructures. Investigators have shown that the assembly of a mechanically resistant hexactinellid sponge is possible with a bottom-up scheme [3]. In that study seven hierarchical levels, ranging from silica nanoparticles arranged circularly around an axial filament to a bundle of square-lattice cylindrical cages, have been identified to contribute to the outstanding mechanical rigidity of the sponge. Research on other biomaterials with hierarchical layers such as diatoms can therefore not only provide insight about their structure and properties, but also offer new concepts and strategies for advanced materials with tailored properties for applications in biotechnology, nanotechnology and others.

Diatoms are single-celled microscopic algae with intricate porous wall structures (frustules) made of silica glass $\left(\mathrm{SiO}_{2}\right)$ [5]. These organisms are found in aqueous environments and their number of species is estimated on the order of hundreds of thousands [6]. There are two general types of diatoms: centric (radially symmetrical) and pennate (bilaterally symmetrical). Each diatom species has a unique shape, size and collection of pores, with diatom sizes varying broadly depending on diatom species (e.g. 10-100 $\mu \mathrm{m}$ in length) [7]. Diatom structures have species-specific shapes and ordered pore arrangements ranging from nm-to- $\mu \mathrm{m}$ length scales [8].

Recent advances in varied techniques have augmented the field of diatom research [9-10]. In fact, the study of diatom biostructures can help toward full understanding of the nature and unique properties of their nanopatterned exoskeleton for biomedical and nanotechnology applications [11]. These 3D micron-size structures with nano-size features can contribute to 
applications such as drug delivery carriers [12], optical and self-assembled devices [12], and nanotemplates [13]. The main motivation for this study is to enhance the understanding of the structure-properties characteristics of real diatom frustules to predict, verify and design silica nanotemplates with tailored geometries for biotechnology and nanotechnology applications. Selected techniques to better characterize nanotemplates [13] and for pore size tuning [14] could complement such manufacturing efforts. The transfer of knowledge from real diatom research to a prospective silica nanotemplate can expedite understanding for different device applications.

Diatom structures have been extensively studied in recent decades primarily for biological purposes, due to their importance in ecosystems and carbon dioxide fixation [15]. However, the research community has recently been focusing on diatom structures because of their micro- and nano-size features, and symmetrical pore arrays, for varied applications such as nanotechnology.

Mechanical analysis and characterization of diatom structures have been pursued mainly using atomic force microscopy (AFM), nanoindentation, and scanning electron microscopy (SEM). Initial studies by Higgins et al. [16] focused on the topography and mechanical properties of adhesive mucilages secreted by the Craspedostauros australis diatom species using AFM. Subsequently, Hamm et al. [6] investigated the mechanical protection offered by the frustule using needle loading tests on several species, discovering an inverse relationship between the frustule size and the force required to break it. Later, in vivo studies of several diatom species by Higgins et al. [17] via AFM determined key morphology features of the diatom frustule. Losic et al. [18] analyzed morphology via SEM and performed AFM-based nanoindentation, mapping the Coscinodiscus diatom frustule, and finding that the elastic modulus varied widely (1.7-15.6 GPa) depending on porosity, thickness and pore size. In further studies, Losic et al. [19] compared morphological features of Coscinodiscus versus Thalassiosira eccentric species, including the 
organization of porous silica layers, topography, pore size, shape and density. Recently, Hildebrand et al. [20] investigated other regions in several diatom biostructures (e.g., valves, girdle bands and bristles) using AFM, enabling visualization of girdle bands at several scales. Additionally, Yao et al. [21] performed nanoindentations on Coscinodiscus diatom frustules at different incident angles (and hence locations) to calculate their elastic modulus and hardness. The investigators reported that these mechanical properties were strongly dependent on the location of the indentation (independent of frustule size), finding varied $E(0.59-2.77 \mathrm{GPa})$ and $H$ values (0.03-0.12 GPa) in the center of the frustule, and a good agreement with Finite Element Method (FEM) simulations. From all previous studies, a variety of mechanical properties of diatom frustules based on nanoindentation have been reported. The challenges of measuring mechanical properties of diatom species experimentally are due to the differences existing between each species and sample preparation. A clear correlation between mechanical properties and diatom features (e.g., porosity, shape, thickness and pore size) has not yet been established. Therefore, modeling across different length scales is necessary to simulate the response of diatom frustules to deformation, in order to facilitate future biosilica nanotemplate design and fabrication. Associated experiments are also required to validate the accuracy of the modeling.

In a combined experimental-simulation study, Hamm et al. [6] reported FEM simulation on the diatom structures of Thalassiosira punctigera species to study the strength of the diatom structure as protective armor against predators. In a recent study, Garcia et al. [22] performed molecular dynamic simulations of diatom-inspired nanoporous materials, investigating the effect of hierarchical nanoporous layers under tensile deformation. The results in that study showed a significant enhancement of the mechanical properties of the material, including superior deformability compared to brittle silica glass. The limited number of similar studies highlights 
the need to examine increased length scales via FEM analysis to calculate the properties of diatom frustules at the microscale.

Researchers have utilized different approaches to address challenges in the fabrication of nanodevices. However, there are still fundamental limitations in the current fabrication methods. In an effort to resolve those challenges, investigators have been studying microorganisms, which have created 3D biostructures, such as diatoms. Several applications have been proposed to use 3D silica structures in optical systems, micro-electromechanical systems, and gas sensors [23].

In this experimental-simulation study, the mechanical response of diatom species to compressive loads was analyzed using ambient nanoindentation and FEM simulation, for predicting and designing tunable properties of future silica nanotemplates. The main objective was to evaluate the mechanical behavior of specific diatom structures for possible size-stiffness, stress-stiffness and size-stress correlations, through a systematic coupled experimentalsimulation procedure. The advantages of this method include the ability to identify optimum properties in bio-inspired structures, study the role of pores and layered structures, and map strategies for device designs. An integrated approach that relies on experiments and simulations together would represent an important milestone in the path towards designing diatom-inspired devices and novel materials.

\section{MATERIALS AND METHODS}

\section{$\underline{2.1 \text { Experimental Section }}$}

\subsubsection{Diatom Species Selection and Initial Preparation}

Diatom species were selected based on ordered pore arrangement and pore size (smaller than $600 \mathrm{~nm}$ ). Vials containing diatom species Coscinodiscus sp. and Synedra sp. (pre-cleaned with nitric acid to remove organic material and debris, and dissolved in $70 \%$ ethanol) were purchased 
from Carolina Biological Supply Company (Burlington, North Carolina). The cleaning process is essential to remove any organic matter from diatoms to make microscopic identification easier and also since it can affect their mechanical properties. The cleaning of diatoms in this study was accomplished via a concentrated acid incubation procedure, followed by several washing steps using distilled water [24]. Cleaned diatom frustules were settled out by centrifugation and stored in $70 \%$ ethanol for further use. The resulting diatom solution contained fully cleaned frustules (optically verified, complete valves and girdle bands) and some broken fossil diatoms.

\subsubsection{Sample Preparation and Optical Analysis}

An adhesive solution was prepared by mixing gelatin and deionized water (e.g., $0.3 \mathrm{~g}$ in $10 \mathrm{ml}$ ) at $60{ }^{\circ} \mathrm{C}$ for 3 minutes. A glass slide was spin-coated with a few drops of the gelatin solution to create a thin film, to increase adhesion between the complete diatom frustules and the slide. One drop of the diatom frustule solution was placed on a gelatin-coated glass slide. The diatom frustule solution was air-dried, and the deposited frustules were arranged using a 3D-printed micromanipulator and a micro-needle via light microscopy (Olympus SZX16 stereomicroscope). Optical images were used to verify when diatoms were free of organic material, as before [24]. Several arranged glass slides containing frustules were prepared similarly and heated up to $30{ }^{\circ} \mathrm{C}$ for about 1 minute to promote further adhesion between frustules and each slide. This sample preparation was found to provide good quality adhesion characteristics (improved over the polyL-lysine method used in prior similar efforts [19] and tested in this study), maintaining diatom frustules in place when considerable forces were applied directly on them with a micro-needle.

\subsubsection{SEM and AFM Morphology Analysis}

Upon successful sample preparation, some diatom slides were sputter-coated with gold and mounted on a SEM stub for additional characterization. Diatom frustule pore sizes and 
arrangements were examined using a SEM (FEI Quanta 200 SEM) equipped with a tungsten filament operated at $30 \mathrm{kV}$. Similar uncoated diatom samples were studied via ambient indentation (described in Section 2.1.4), with SEM images produced for analysis of frustule morphology. AFM imaging was accomplished separately by mounting clean diatom samples on a glass slide (using the same procedure as in Section 2.1.2 to securely fix them in place) and using a NT-MDT Solver Next AFM microscope and Bruker NCHV-A probes, with a spring constant of $42 \mathrm{~N} / \mathrm{m}$ and resonant frequency of $300 \mathrm{kHz}$ in intermittent contact (tapping) mode.

\subsubsection{Ambient Nanoindentation Testing and Analysis}

Diatom samples were prepared as described previously in Section 2.1.2. To ensure the diatom sample was on a flat surface prior to ambient nanoindentation, the glass slide was attached to cured casting resin holders using mounting adhesive (Ted Pella Crystalbond ${ }^{\mathrm{TM}}$ 509). Ambient nanoindentation was performed on the top surface of entire diatom frustules via a MTS Nano Indenter $^{\circledR} \mathrm{XP}$ equipped with a diamond Berkovich tip (radius: $20 \mathrm{~nm}, E: 1,141 \mathrm{GPa}$ and Poisson's ratio: 0.07 [25]). To identify the maximum load that could be applied on the diatom, a method of G-series continuous stiffness measurement (CSM) standard hardness, modulus, and tip calibration was used, with a maximum displacement of $200 \mathrm{~nm}$. The allowable drift rate was set to be $0.05 \mathrm{~nm} / \mathrm{s}$ before nanoindentation was initiated. Surface approaching velocity was 10 $\mathrm{nm} / \mathrm{s}$. A maximum load range of 10 to $30 \mu \mathrm{N}$ was identified from the CSM method. Subsequently, a G-series basic hardness and modulus load control method was applied to obtain load vs. displacement $(p-h)$ curves for different diatom frustules. The peak-load holding time was 10 seconds. Key mechanical properties were calculated from the $p-h$ curves via the Oliver-Pharr relationship [25], using the software Dureza [26]. A Poisson's ratio of 0.17 was used for the diatom frustule, as previously reported [27]. Analysis of the indenter $p-h$ curves allowed the 
calculation of the Young's modulus and hardness of the diatom frustule as defined by Oliver and Pharr [25]. When the tip geometry and related parameters are known, both $H$ and $E$ can be calculated via Equations 1-2 [25], where $H$ is determined by $P_{\max }$ (the peak indentation load) and $A$ (the nanoindentation contact area), $E_{r}$ is the reduced Young's modulus and $S$ is the slope of the unloading curve. The sample Young's modulus $E_{\text {sample }}$ is calculated via Equation 3 [25], where $v_{\text {sample }}$ and $v_{\text {indenter }}$ are the Poisson's ratio of the sample and indenter respectively, and $E_{\text {indenter }}$ is the Young's modulus of the indenter.

$$
\begin{gathered}
H=P_{\max } / A \\
E_{r}=\sqrt{\pi} / 2 * S / \sqrt{A} \\
1 / E_{r}=\left(1-v_{\text {sample } \left.^{2}\right) / E_{\text {sample }}}+\left(1-v_{\text {indenter }}{ }^{2}\right) / E_{\text {indenter }}\right.
\end{gathered}
$$

\subsection{Simulation Section}

\subsubsection{Diatom Model Creation via Computer-Aided Design (CAD) Software}

SEM images of the diatom frustules obtained were used for creation of precise 3D diatom models via CAD software Pro/ENGINEER Wildfire version 4.0. Real diatom frustules in nature are made of two dome-shaped structures (or valves) joined as the parts of a "Petri dish". Each 3D diatom model was simplified to include only the top valve (epitheca) of each frustule, flat-shaped with key features (e.g., pores), to reduce the computational cost. 2D models of the contour of diatom frustules were first created with dimensions measured from SEM images, and extruded to the appropriate diatom height. The resulting solid 3D models were then hollowed, and pores and slits were added as per the SEM micrographs. The porosity for a given diatom frustule was calculated using Equation 4, determined by $A_{\text {empty }}$ (empty area per pores) and $A_{\text {total }}$ (total surface area). Here also, $d$ is the pore diameter, $D$ is the frustule diameter, and $N$ is the number of pores.

$$
\% \text { Porosity }=A_{\text {empty }} / A_{\text {total }} * 100=N(d / D)^{2} * 100
$$




\subsubsection{Simulation Setup, Critical Parameters and FEM-based Software}

The mechanical properties of the diatom frustules measured experimentally, and suitable 3D diatom models, were used as the primary input elements for FEM simulations. These essential data fully defined an initial FEM diatom model (specific $E$, frustule morphology) for subsequent studies of structure-property relations and property variation between diatom species. The mechanical response of the diatom models was first validated against nanoindentation experimental results, subsequently evaluated using uniform compression FEM simulations, and compared with experimental results and independent studies (described in Section 2.2.3). Loads applied in all compression simulations of diatom frustules in this study were similar to the nanoindentation experiments and other independent tests [6], as summarized in Section 3.

A mesh of tetrahedral finite elements was generated via COMSOL Multiphysics version 4.3b, and a linear geometry solver was selected to describe the elastic response (i.e., small deflections) of the diatom frustule under compression. On simulated loading, the mesh was monitored until the stresses converged, with a final average mesh density ranging between 36,500-69,800

elements per $\mu \mathrm{m}^{3}$ depending on diatom geometry and pore size, with a higher concentration of elements located at the top of a given frustule for improved accuracy. Various diatom frustules were simulated in the same way to ensure that the observed behavior solely reflected the loaddiatom interactions and not a given imposed boundary condition or convergence artifacts.

\subsubsection{FEM Simulation Methods and Post-processing Analysis}

Experimental data and FEM nanoindentation simulations were first used to reproduce nanoindentation conditions and validate each calculated $p$ - $h$ curve for a given diatom frustule. 3D diatom models, with epitheca frustules only, were imported into COMSOL, and a simulated diamond Berkovich nanoindenter tip (as in Section 2.1.4) was modeled with a $65.27^{\circ}$ face angle. 
A section of the 3D model was simulated to decrease simulation time. The species-dependent Young's moduli of the diatom frustules obtained from nanoindentation experiments were used to uniquely define each model, as well as the reported Poisson's ratio. A contact pair was defined between the simulated indenter and the diatom model, allowing both materials to interact. The mesh was smaller in the diatom model than in the indenter to ensure the contact conditions were met at the interface and to minimize convergence issues. A fixed boundary (no movement along $x$-, $y$-and $z$-axis) was applied at the bottom surface of the diatom model, while the top face of the indenter was set with a prescribed displacement (along the $z$-axis). The indenter lateral faces were restricted from movement in the $x$ - or $y$-direction to avoid shifting or sliding. The resultant loads at the contact boundary were evaluated, and plotted versus the prescribed indenter displacement. Each calculated $p$ - $h$ curve was compared with its associated experimental $p-h$ curve, and its slope used to verify that the elastic region was reproduced as in the experiments.

Once the simulated $p$ - $h$ curves were validated, FEM compression simulations were then performed on each diatom model. This allows evaluation of relevant fabrication conditions for nanotemplates (e.g., uniform loading) where experimental data are not readily available. As before, SEM images and properties of experimental frustules from ambient nanoindentation were used to distinctively define each diatom model. Complete 3D CAD diatom models, with epitheca only, were created for uniform compression simulations using an appropriate mesh depending on diatom species. 3D CAD diatom models were imported into COMSOL, and a uniform compressive experimental load was simulated with its corresponding value as in the nanoindentation experiments and independent tests [6]. A fixed boundary was applied at the bottom surface of the diatom model to avoid shifting or sliding, while the top frustule surface had a predefined load ( $z$-axis) similar to experiments. The lateral faces of the diatom model were 
unrestricted to allow deformation. Mechanical responses such as the displacement and von Mises stress distributions were subsequently analyzed for each frustule as a function of porosity.

Analyses of the displacement and von Mises stress distributions were achieved within COMSOL via Equations 5-6 [28]. The displacement $x$ is defined (Eq. 5) as the motion vector of each point within a solid, or $u[X, t]$, where $u$ is the displacement vector, $X$ is the initial position and $t$ is time [29]. The von Mises stress $\sigma_{\text {mises }}$ (Eq. 6) represents the multi-axial stress state of a solid described by the three principal stresses $\left(\sigma_{1}, \sigma_{2}\right.$ and $\left.\sigma_{3}\right)$, and often used as a failure criterion when compared to the yield strength of a given material [29]. Hence, Equation 5 is used to calculate the displacement of a top frustule along the compressive load direction, and Equation 6 to determine the maximum effective (von Mises) stress at a given point in a 3D diatom model.

$$
\begin{gathered}
\boldsymbol{x}=\boldsymbol{x}(\boldsymbol{X}, t)=\boldsymbol{X}+\boldsymbol{u}(\boldsymbol{X}, t) \\
\sigma_{\text {mises }}=\sqrt{\frac{1}{2}\left(\sigma_{1}-\sigma_{2}\right)^{2}+\left(\sigma_{1}-\sigma_{3}\right)^{2}+\left(\sigma_{2}-\sigma_{3}\right)^{2}}
\end{gathered}
$$

\section{RESULTS}

\subsection{Experimental Section}

\subsubsection{Morphology Before and After Nanoindentation using SEM and AFM}

Fig. 1 shows representative SEM images of a Coscinodiscus sp. diatom frustule (Fig. 1(a-c)), emphasizing its ordered pore arrangement at the microscale, and an elongated Synedra sp. diatom frustule (Fig. 1(d-f)) showing its characteristic longitudinal slits. Table 1 summarizes key frustule dimensions measured in this study to be used in simulations. AFM analysis of these diatoms provides additional insights into their detailed morphology. As depicted in Fig. 2, a layer of the centric frustule (Fig. 2(a-c)) evaluated via AFM exhibited a mesh-like structure with a regular pore pattern. Similar AFM analysis of the Synedra sp. frustule (Fig. 2(d-f)), indicated this elongated frustule structure had distinct slits and ribs, arranged in a highly ordered fashion. 
(Please see attached figures file)

Fig. 1. (Color online/print) SEM micrograph of a characteristic Coscinodiscus sp. diatom frustule (a-b) and a Synedra sp. diatom frustule (d-e) examined prior to nanoindentation experiments. The biosilica centric frustule (a) has a diameter $\sim 200 \mu \mathrm{m}$ and a highly ordered pore arrangement $(\mathrm{b})$, which varies in size $(d \sim 4.8 \mathrm{~nm})$ and orientation. The pennate frustule (d) has a length $l$ of $\sim 160 \mu \mathrm{m}$, a width $w$ of $\sim 7 \mu \mathrm{m}$, and contains valve surfaces with distinct features such as lateral longitudinal structures (e) with a thin slit width $s$ of $\sim 0.4 \mu \mathrm{m}$ (blue arrow) and a rib thickness $t$ of $\sim 0.5 \mu \mathrm{m}$ (orange arrow). Representative SEM images of these diatom frustules reveal distinct types of indent marks after nanoindentation tests. Centric frustule image (c) shows surface pits and an extended crack shown via red arrows. Pennate diatom image (f) depicts a longitudinal crack, which reaches one end of the frustule after nanoindentation.

Table 1. Diatom frustule dimensions obtained from SEM images and used in simulations.

\begin{tabular}{|c|c|c|c|c|c|c|c|c|c|}
\hline $\begin{array}{c}\text { Coscinodiscus sp. } \\
\text { Frustule }\end{array}$ & $\begin{array}{c}D \\
(\mu \mathrm{m})\end{array}$ & $\begin{array}{c}T \\
(\mu \mathrm{m})\end{array}$ & $\begin{array}{c}d \\
(\mu \mathrm{m})\end{array}$ & $\begin{array}{l}\text { Synedra sp. } \\
\text { Frustule }\end{array}$ & $\begin{array}{c}l \\
(\mu \mathrm{m})\end{array}$ & $\begin{array}{c}w \\
(\mu \mathrm{m})\end{array}$ & $\begin{array}{c}T \\
(\mu \mathrm{m})\end{array}$ & $\begin{array}{c}s \\
(\mu \mathrm{m})\end{array}$ & $\begin{array}{c}t \\
(\mu \mathrm{m})\end{array}$ \\
\hline Average & 200 & 1 & 4.8 & Average & 160 & 7 & 1 & 0.4 & 0.5 \\
\hline
\end{tabular}

3D pore structure and number of layers: hierarchical stacking of 3 porous layers for Coscinodiscus sp., and rib-slit structure with no observable hierarchical arrangement for Synedra sp.

(Please see attached figures file)

Fig. 2. (Color online/print) AFM image of a centric Coscinodiscus sp. diatom frustule (a-c) displaying its ordered mesh-like porous structure (a) and a hierarchical layered structure (b), and its corresponding depth-distance profile (measured along a line shown in green) from the layer of the frustule (c), revealing a regular pore pattern. The pennate Synedra sp. diatom frustule (d-f) shows its elongated structure (d) with characteristic ribs and slits (e), and its related depth-distance profile (measured along its corresponding green line) from the top layer of the frustule (f), displaying an ordered slit pattern.

Upon selection and evaluation of various Coscinodiscus sp. and Synedra sp. diatom frustules, ambient nanoindentation testing was performed on each top frustule surface, followed by SEM characterization of these diatom structures to evaluate their morphologies after nanoindentation.

Fig. 1(c) and (f) illustrate typical SEM images of some of the biostructures evaluated after nanoindentation, highlighting the differences in indentation response.

\subsubsection{Ambient Nanoindentation: Load-Displacement Curves and Elastic Modulus}

Fig. 3 displays representative $p$ - $h$ curves illustrating the relatively low stiffness values of the top diatom frustules compared with bulk silica glass (73 GPa). It is also apparent that the pennate diatoms (Fig. 3(c-d)) have $\sim 5$ times or greater Young's moduli and hardness values than the centric diatoms (Fig. 3(a-b)), and such elongated frustules display significantly less displacement upon ambient nanoindentation than their rounded frustule counterparts. A summary of the 
experimental measurements for both diatom species is provided in Table 2. The standard deviation variation of the mechanical response of the centric diatoms is likely due to the sizedependence $(D)$ of the tested frustules, as previously reported [6].

(Please see attached figures file)

Fig. 3. (Color online/print) Ambient nanoindentation curves: characteristic experimental determinations of Young's moduli for Coscinodiscus sp. diatom frustules (a-b) show that values are low (average $E=3.1 \mathrm{GPa}$ ) compared to the value for bulk silica glass $(73 \mathrm{GPa}$ ). Additional nanoindentation curves: representative experimental measurements of Young's moduli for Synedra sp. diatom frustules (c-d) show that values are significantly higher (average $E=16.6$ GPa) compared to the Coscinodiscus sp. diatom frustules. Nanoindentation was applied to the top frustule surfaces.

Table 2. Experimental data obtained from the selected diatom frustules in this study.

\begin{tabular}{|c|ccccc|}
$\begin{array}{c}\text { Coscinodiscus sp. } \\
\text { Frustule ID }\end{array}$ & $\begin{array}{c}\boldsymbol{E} \\
(\mathbf{G P a})\end{array}$ & $\begin{array}{c}\boldsymbol{H} \\
(\mathbf{G P a})\end{array}$ & $\begin{array}{c}\text { Synedra sp. } \\
\text { Frustule ID }\end{array}$ & $\begin{array}{c}\boldsymbol{E} \\
(\mathbf{G P a})\end{array}$ & $\begin{array}{c}\boldsymbol{H} \\
(\mathbf{G P a})\end{array}$ \\
\hline C-2 & 3.8 & 0.11 & $\mathrm{~S}-28 \mathrm{a}$ & 13.7 & 0.85 \\
C-6 & 1.1 & 0.11 & $\mathrm{~S}-28 \mathrm{~b}$ & 15.7 & 1.08 \\
C-12 & 1.5 & 0.26 & $\mathrm{~S}-28 \mathrm{c}$ & 18.6 & 1.14 \\
C-13 & 5.6 & 0.10 & $\mathrm{~S}-28 \mathrm{~d}$ & 18.4 & 1.41 \\
C-14 & 1.7 & 0.23 & - & - & - \\
C-20 & 6.2 & 0.34 & - & - & - \\
C-21 & 10.6 & 1.03 & - & - & - \\
Mean $^{*}$ & 3.1 & 0.17 & Mean^ & 16.6 & 1.12 \\
Standard deviation $^{\#}$ & 2.7 & 0.24 & Standard deviation & 2.3 & 0.23 \\
\hline
\end{tabular}

Young's moduli for tested diatom frustules: Coscinodiscus sp. $E_{a v g}=3.1 \mathrm{GPa}$ and Synedra sp. $E_{\text {avg }}=16.6 \mathrm{GPa}$.

Number of tested frustules: 10 (centric), 3 (pennate). A load of $10 \mu \mathrm{N}$ was applied in most cases.

Mean and standard deviation using: 17 indentations (centric), 5 indentations (pennate).

\section{$\underline{3.2 \text { Simulation Section }}$}

\subsubsection{FEM Nanoindentation and Validation}

As per Section 2.2.3, experimental data (e.g., displacement) and nanoindentation simulations were first used to mimic nanoindentation test conditions and validate the simulated indenter $p$ - $h$ curves. The 3D CAD diatom models were imported into COMSOL and a Berkovich nanoindenter tip was modeled to reproduce the tip-sample interaction during nanoindentation tests. For efficient computation, only a section of the 3D diatom model was used to simulate the experimental frustule deformation. Each diatom frustule model was assigned the corresponding experimentally determined average Young's modulus to define it uniquely. The resultant $p-h$ curves of the simulated models were monitored for convergence and compared with the experimental measurements to verify their validity. The nanoindentation simulation setup and 
associated simulated $p$ - $h$ curve were found in reasonable agreement with experiments in the elastic region (see Fig. S1 in Supplementary Data). Thus, it is assumed that a similar method is applicable for other experiments such as uniform compression, also in the elastic region. Maximum displacement was imposed for the nanoindentation simulations, as experimental displacement data was known. It is also assumed in this study that uniform compression simulations monitoring frustule deformation will be valid for small displacements, e.g. $<40 \mathrm{~nm}$.

\subsubsection{FEM Compression and Mechanical Properties}

Experimental data (e.g., load) and uniform compression simulations were used to examine the mechanical response of various diatom models. 3D CAD diatom models (of flat-shaped epitheca only) were studied using varied test loads depending on the diatom species. A specific load $P$ corresponding to experimental data was imposed for each compression simulation (Coscinodiscus sp. and Synedra sp. $P=10 \mu \mathrm{N}$ (maximum load used in nanoindentations) and $F$. kerguelensis $P=750 \mu \mathrm{N}$ (load reported before [6])). Simulation parameters were monitored to reproduce experimental conditions and to ensure convergence of results. A suitable mesh of tetrahedral elements, depending on the diatom species, was used in all simulations in this study.

Mechanical response via von Mises stress and displacement distributions was analyzed for each diatom model upon uniform compression simulation as shown in Fig. 4-6. In each case, a suitable 3D model of the diatom frustule as in nature was simulated first, with its measured dimensions (e.g., frustule diameter $D$, pore diameter $d$ ) from SEM images and $E$ similar to the nanoindentation experiments and other independent tests [6]. For the centric diatom frustule, the smallest feasible $d$ value was used due to current software limitations. The displacements of the simulated models were compared with the corresponding experimental displacements to verify 
their validity. Next, a "modified" diatom model was simulated with the largest pores or smallest slits depending on the diatom species (values shown in Fig. 4-6), as suitable for varied templates.

(Please see attached figures file)

Fig. 4. (Color online/print) FEM uniform elastic compression simulation of Coscinodiscus sp. diatoms (epitheca only, $D=200 \mu \mathrm{m}$ ). Top figures show displacement (a) and stress distributions (b) for models similar to those found in nature $(d=4.8 \mu \mathrm{m})$. Bottom figures (c)-(d) show equivalent results when $d$ is increased, relevant for microtemplate applications $(d=12 \mu \mathrm{m})$. Views above each 3D model show features of each distribution without displacement. Dimensions of the "modified" diatom frustule models and calculated mechanical properties are included in Table 3.

Results in Fig. 4 show the extent of the displacement of the top surface of the centric diatom frustule, primarily in the center and decreasing radially outward toward the edge of the structure (Fig. 4(a) and (c)), and predict a modest stress distribution in the center of the diatom frustule top surface, and a lower stress distribution around the sides of the structure (Fig. 4(b) and (d)). While the Young's modulus used for the centric diatom models was $2.3 \mathrm{GPa}$, different than in experiments, $3.1 \mathrm{GPa}$ (Table 2), such value is within the range obtained from experiments.

Synedra sp. diatom models were created as previously using SEM micrographs, and their mechanical behavior was also analyzed upon uniform compression simulations. Displacement and von Mises stress distributions were evaluated for each diatom model as shown in Fig. 5.

(Please see attached figures file)

Fig. 5. (Color online/print) FEM uniform elastic compression simulation of Synedra sp. diatom frustules (epitheca only, length $l=162 \mu \mathrm{m}$, width $w=8 \mu \mathrm{m}$, and rib thickness $t=0.60 \mu \mathrm{m}$ ) shows displacement (a) and stress distributions (b) of the top surface for frustules typically found in nature (slit width $s=0.54 \mu \mathrm{m}$ ). Figures (c)-(d) show the effect of decreasing this dimension $(s=0.135 \mu \mathrm{m})$, keeping $t=0.60 \mu \mathrm{m}$ constant, thus increasing the number of slits and ribs. Close-up views above each 3D model show each distribution without displacement. Table 3 depicts relevant data.

Results from the Synedra sp. diatom frustule (Fig. 5) indicate similar displacement distributions on the diatom models, mainly in the center of the top surface around ribs and decreasing toward the remaining structure (Fig. 5(a) and (c)). Simulation also predicts low stress distributions in the top frustule (Fig. 5(b) and (d)), however for frustules with thinner slits (Fig. 5(d)) a more uniform stress distribution, with lower overall values, is observed. 
The evaluation of another important diatom frustule model, F. kerguelensis, was also pursued via FEM simulations to predict its mechanical response as illustrated in Fig. 6. A summary of dimensional values and predicted properties of all diatom models is included in Table 3.

(Please see attached figures file)

Fig. 6. (Color online/print) FEM uniform elastic compression simulation of pennate (F. kerguelensis) diatom frustules (epitheca only, frustule length $l=30 \mu \mathrm{m}$, and frustule width $w=7.83 \mu \mathrm{m}$ ). Top figures show displacement (a) and stress distributions (b) for models with dimensions and pore sizes as in nature $(d=0.3 \mu \mathrm{m})$. Bottom figures (c)(d) reveal differences for the "modified" frustules when pore size is increased $(d=0.7 \mu \mathrm{m})$. As before, close-up views of each distribution without displacement are shown and dimensions of the "modified" frustules and properties are found in Table 3.

Results from the F. kerguelensis diatom (Fig. 6) indicate unusually lower displacement of the top frustule surface (Fig. 6(c)) compared to the equivalent model as found in nature (Fig. 6(a)) given the load applied, mainly in the center and decreasing toward the remaining structure. Simulation also predicts stress distributions in the center of the frustule top surface (Fig. 6(d)) are similar to those in the natural models (Fig. 6(b)), particularly near the center and edges, but with a higher maximum stress level (see Table 3). Dimensions used in simulations vary (Table 1).

Table 3. Experimental and simulated data from real and "modified" diatom frustule models respectively.

\begin{tabular}{|c|c|c|c|c|c|c|}
\hline $\begin{array}{l}\text { Diatom } \\
\text { Species }\end{array}$ & $\begin{array}{c}\text { Number of } \\
\text { Pores or Slits } \\
\text { [Expt.] } \\
N\end{array}$ & $\begin{array}{l}\text { Pore Diameter } \\
\text { or Slit Width } \\
\text { [Expt.] } \\
d \text { or } s(\mu \mathrm{m})\end{array}$ & $\begin{array}{c}\text { Number of } \\
\text { Pores or Slits } \\
\text { [Sim.] } \\
N\end{array}$ & $\begin{array}{l}\text { Pore Diameter } \\
\text { or Slit Width } \\
\text { [Sim.] } \\
d \text { or } s(\mu \mathrm{m})\end{array}$ & $\begin{array}{c}\text { Maximum } \\
\text { Displacement } \\
\text { [Sim.] } \\
(\mu \mathrm{m})\end{array}$ & $\begin{array}{c}\text { Maximum } \\
\text { von Mises Stress } \\
\text { [Sim.] } \\
\left(\mathrm{N} / \mathrm{mm}^{2}\right)\end{array}$ \\
\hline Coscinodiscus sp. & 2,112 & 0.60 & 69 & 12.0 & 0.94 & 4.4 \\
\hline Synedra sp. & 146 & 0.54 & 210 & 0.135 & $7.6 \times 10^{-5}$ & 0.4 \\
\hline F. kerguelensis & 163 & 0.30 & 77 & 0.70 & 0.35 & 1595 \\
\hline
\end{tabular}

Young's moduli used in simulations vary per diatom species, such values are within the range obtained from experiments in this study (Table 2) or independently: E=2.3 GPa (Coscinodiscus sp.), $16.6 \mathrm{GPa}$ (Synedra sp.), and 22.4 GPa (F. kerguelensis) [6]. Loads $P$ applied in compression simulations: $P=10 \mu \mathrm{N}$ (maximum load used in nanoindentations, Coscinodiscus sp. and Synedra sp.) and $750 \mu \mathrm{N}$ (similar to that used by Hamm et al. [6], F. kerguelensis).

The mechanical behavior of the Coscinodiscus sp. diatom frustules was evaluated further for possible size-stiffness, stress-stiffness and size-stress correlations. Fig. 7(a-b) shows the distinct relationships observed between the experimental Young's modulus E (Table 2), measured frustule diameters $D$, and associated calculated maximum von Mises stress values. Fig. 7(a) shows a nearly normal distribution plot between $D$ and the experimental $E$ with a peak value 
corresponding to a centric frustule with $D \sim 200 \mu \mathrm{m}$ (and associated $E \sim 11 \mathrm{GPa}$ ). A similar normal distribution relationship exists between the maximum von Mises stress and experimental $E$ for this frustule (a peak von Mises stress value at $\sim 30 \mathrm{~N} / \mathrm{mm}^{2}$ ), as shown in Fig. 7(b). This curve is approximately a mirror-reversal of Fig. 7(a) across the vertical axis. An inverse linear trend is observed between $D$ and the maximum von Mises stress calculated for this frustule (Fig. 7(c)).

(Please see attached figures file)

Fig. 7. (Color online/print) Correlations observed in this study in the behavior of centric Coscinodiscus sp. frustule in experiments and compression simulations: (a) frustule diameter $D$ vs. experimental Young's modulus $E$, (b) maximum von Mises stress vs. experimental Young's modulus $E$, and (c) frustule diameter $D$ vs. maximum von Mises stress. Guidelines denote traits $\left(D \sim 200 \mu \mathrm{m}, E \sim 11 \mathrm{GPa}\right.$, von Mises stress $\left.\sim 30 \mathrm{~N} / \mathrm{mm}^{2}\right)$ for an optimal Coscinodiscus sp. diatom frustule.

To estimate the effect of porosity (e.g., $d$ and $N$ ), selected diatom models with specific dimensions (Eq. 4) were created and their mechanical properties were analyzed upon FEM uniform compression simulations. Fig. 8(a) shows the resultant properties using Coscinodiscus $s p$. diatom models similar to those found in nature $(D=200 \mu \mathrm{m}, E=2.3 \mathrm{GPa})$ with increasing pore diameter, while keeping the number of pores constant $(N=61)$. Fig. 8(b) reveals the calculated properties for identical centric models $(D=200 \mu \mathrm{m}, E=2.3 \mathrm{GPa})$ with increasing number of pores, and maintaining pore diameter constant $(d=9.6 \mu \mathrm{m})$. Results for the F. kerguelensis diatoms (Fig. 8(c)) show the calculated properties using frustule models similar to those in nature $(L=30 \mu \mathrm{m}$, $E=22.4 \mathrm{GPa}[6])$ while conserving the number of pores $(N=77)$. Fig. 8(d) illustrates the findings for analogous diatom models $(L=30 \mu \mathrm{m}, E=22.4 \mathrm{GPa}[6])$ with a constant pore size $(d=0.4 \mu \mathrm{m})$.

(Please see attached figures file)

Fig. 8. (Color online/print) Effect of (a) pore diameter and (b) number of pores on selected mechanical properties upon FEM uniform elastic compression simulations for centric Coscinodiscus sp. diatom models. Similar analysis of the role of (c) pore diameter and (d) number of pores on mechanical properties for pennate F. kerguelensis diatom models is included. 


\section{DISCUSSION}

Coscinodiscus sp. diatom samples were characterized via SEM and AFM prior to nanoindentation experiments in this study in terms of frustule morphology and hierarchical structure. AFM data reveal that these centric frustules have top surfaces made of a few layers of ordered mesh-like porous structures. The evaluated layer of the Coscinodiscus sp. diatom frustule was found to have regular pores, in excellent agreement with independent studies [1819]. AFM evaluation of the pennate Synedra $s p$. diatom shows the elongated frustules have valve surfaces with highly ordered longitudinal slits and ribs.

Analysis of the nanoindentation results indicates that the Coscinodiscus $s p$. diatom frustules show considerably lower Young's moduli values (1.1-10.6 GPa) compared with that of bulk silica glass (73 GPa). Yao et al. [21] measured lower $E$ values $(0.59-2.77 \mathrm{GPa})$ for this centric diatom species using similar nanoindentation conditions. Similar to Yao et al., nanoindentations were performed primarily on the top frustule of the diatom species. The difference in Young's moduli reported here compared to that work may be explained by the larger number of diatoms tested in this study (Table 2), allowing for additional statistical analysis and increased confidence in the reproducibility of the nanoindentation data. A large variation in elastic modulus exists for Coscinodiscus sp. diatom frustules, probably due to each specific frustule dimension and associated layered structure. The Coscinodiscus sp. frustule diameters tested varied from about 50 to $300 \mu \mathrm{m}$ (Fig. 7), values which are within the broad range reported in the literature [21].

Further examination of the nanoindentation results in this study reveals that the Synedra $s p$. diatom frustule shows significantly higher Young's moduli values (13.7-18.6 GPa) compared to those of the Coscinodiscus sp. diatom frustules. These results are still low compared to that of bulk silica glass. To the authors' knowledge, these nanoindentation data on the Synedra sp. are 
reported here for the first time. A smaller number of nanoindentation measurements from a Synedra sp. diatom frustule were obtained in this study, because the results were found to be reproducible (Table 2) due to a more controlled nanoindentation (i.e. the center of ribs). The large variation in the mechanical response of the two studied diatom species is hypothesized to be attributed to different factors, including the position of the indenter on the sample, the flatness of samples, variability in indentation as per changes in density of the biosilica material (e.g. pennate ribs vs. centric layer), and frustule morphology and porosity.

The simulation techniques used in this study involved the validation of the nanoindentation conditions and reproduction of experimental displacement values per diatom species. Since the nanoindentation simulations reproduced well the experimental behavior, a similar method was used to simulate uniform compression on the diatom frustules in the elastic region. Particularly, FEM nanoindentation simulation resulted in a good agreement for small displacements (Fig. S1).

The selection of pore and slit size were varied depending on the diatom model. For the centric diatom frustules (Coscinodiscus sp.), the "modified" model aimed to evaluate mechanical behavior for the largest possible pore size (with converged stresses) to investigate its effect on future fabricated structures where large $d$ values may be desired. For the pennate diatoms (Synedra sp. and Kerguelensis sp.), specific slit widths and pore diameters were used respectively, based on potential nano- and microtemplate applications [12].

Analysis of the FEM compression simulations in this study reveals that the Coscinodiscus sp. diatom frustules show distinct displacement and uniform stress distributions similar to those found in nature (Fig. 4). When $d$ is increased for potential microtemplate applications, a comparable displacement distribution and a lower stress distribution around the sides of the frustule structure are observed. This implies that increasing the pore diameter in this diatom 
species (or similar diatom-inspired structures) can lead to a robust frustule that retains its ability to bend (i.e., displacement distribution) while distributing lower stresses (i.e., von Mises stress distribution) in critical areas such as the pores and sides compared to the stresses found in nature.

Further analysis of the FEM compression simulations reveals that the Synedra sp. diatom frustules show less uniform displacement and stress distributions (Fig. 5) compared to the centric diatoms. Possible reasons for the small displacements calculated include the use of a higher experimental $E$ (versus the Coscinodiscus sp.) and high aspect ratio (i.e., elongated frustule). When $s$ is decreased for potential nanotemplate applications, similar displacement distributions are calculated but a more uniform (and lower) stress distribution around the ribs and sides of the frustule structure is observed. These findings suggest that fabricating a frustule with these characteristics can lead to a versatile structure, one which retains its ability to bend, but undergoes lower stresses in critical areas such as slits, ribs and frustule sides compared to the diatom species in nature. Success in this effort would rely on the resolution of the fabrication technique (e.g., etching) required to create ultrathin slits and other nanotemplate geometries.

Examination of additional FEM compression simulations indicates that the "modified" $F$. kerguelensis diatom frustule shows an anomalous displacement distribution yet a similar stress distribution compared to diatoms in nature (Fig. 6). The latter is consistent with findings by Hamm et al. [6] of equivalent stress distributions for this species. As Fig. 6(c) shows, when $d$ is increased for possible microtemplate application dimensions, a remarkably lower displacement distribution around pores and sides of the frustule is achieved in the simulation. This implies that fabrication of frustule structures with such morphological characteristics may effectively lead to less rigid structures than described for the Synedra $s p$. frustule. Thus, for the F. kerguelensis frustule, increasing $d$ may lead to a decreased ability to bend, probably due to its intricate 
structure, while retaining its ability to sustain stress levels (in pores and frustule sides) compared to the diatom in nature. The evaluated pore size is within the resolution of current fabrication methods, and additional systematic and integrated studies are needed for application purposes.

The mechanical properties of the Coscinodiscus sp. diatom frustules were further evaluated for possible size-stiffness, stress-stiffness and size-stress correlations (Fig. 7). Analyses using the experimental Young's moduli (Table 2), measured frustule diameters, and calculated maximum von Mises stress values reveal anomalous trends for this frustule geometry. An inverse linear trend was observed between the frustule diameter and the maximum von Mises stress sustained by the centric diatom. Additionally, a nearly normal distribution trend was found between the measured $D$ and the experimental $E$. A similar normal distribution was detected between the maximum von Mises stress and the experimental $E$. These trends indicate that the optimal Coscinodiscus sp. diatom frustule will have certain traits $(D \sim 200 \mu \mathrm{m}, E \sim 11 \mathrm{GPa}$ and stress $\sim 30$ $\mathrm{N} / \mathrm{mm}^{2}$ ), which can be useful for applications where larger modulus and smaller von Mises stress values are required. Further nanomechanical studies of the effect of frustule geometry on varied properties (and other diatom frustules) are needed to confirm such correlations.

The effect of porosity on the mechanical properties upon uniform compression simulations was evaluated in this study for diatom frustules containing pores only (Fig. 8). The Synedra sp. frustules were not included in this analysis due to their complex valve surface microstructures with slits. As pore diameter increases (Fig. 8(a)), the Coscinodiscus sp. frustule showed increasing trends for the von Mises stress, displacement and elastic strain energy density values. Similar overall trends are observed for this frustule when the number of pores $N$ increases (Fig. 8(b)). These results indicate this centric frustule is fairly deformable, with an approximately linear relationship between the porosity and the von Mises stress. This finding correlates well 
with prior studies [21], which reported that this diatom stiffness is linearly related to porosity. In contrast, the $F$. kerguelensis frustule exhibited more complex behaviors as porosity varied. Overall, trends show a decrease and leveling off (i.e., quickly becoming constant) of von Mises stress and elastic strain energy density levels as $d$ increases, while displacement values remain unchanged. Similar leveling off of these mechanical traits is observed as $N$ increases. It is noteworthy that the simulated mechanical property values of the F. kerguelensis frustules were significantly larger (an order of magnitude) compared to those of the Coscinodiscus sp. frustules. The large variation in the mechanical behavior of these frustules is related to different factors affecting the simulations, including the diatom morphology, experimentally-reported Young's moduli, load, pore diameter and type of finite element mesh used (species dependent). Trends also indicate that the distribution of pore sizes plays a more significant role on the mechanical behavior of larger centric frustules (Fig. 8) compared to the frustule diameter (Fig. 7).

Experimental stiffness values and SEM information, used to uniquely define each diatom frustule model, efficiently facilitate the study of their material properties via FEM simulations. Furthermore, simulated $p$ - $h$ profiles were satisfactorily validated with experiments. Most significantly, the effect of diatom frustule morphology (pennate) is reported for the first time in this study. Results show that these frustule morphologies differ in their mechanical behavior under uniform compression conditions. In particular, this study reveals distinct displacement and von Mises stress distributions depending on the diatom species and pore diameter or slit width. Additional simulation studies of varied 3D diatom models with hierarchical geometries and resultant properties will be important to determine the configurations best suited for nanotemplate applications. These necessarily more complex FEM simulations may be constrained by the computational resources or time required by the model geometry or 
simulation conditions. Furthermore, nanoindentation measurements are also needed to more precisely determine the elastic moduli of scarce diatom frustules (e.g., F. kerguelensis), which will then allow more methodical simulations.

\section{CONCLUSIONS}

In summary, systematic experimental-simulation studies of the structure and mechanical behavior of diatom species show remarkable size-dependent Young's moduli, hardness and von Mises stresses, mainly due to dominant porosity and frustule morphology. Microscopy revealed two distinct diatom species structures. Centric Coscinodiscus sp. frustules comprised of porous layers, with both circular and irregular pores. Pennate Synedra sp. frustules consisted of elongated valve surfaces with lateral slits and ribs, displaying ordered slit patterns. An integrated procedure to evaluate the mechanical response of any diatom shape via ambient nanoindentation experiments and FEM simulations was developed. Nanoindentation measurements for the Coscinodiscus sp. frustules revealed a range of $E$ and $H$ between 1.1-10.6 GPa and 0.10-1.03 GPa, respectively. Nanoindentation results for the Synedra $s p$. frustules indicated significantly higher $E$ and $H$ values ranging between $13.7-18.6 \mathrm{GPa}$ and $0.85-1.41 \mathrm{GPa}$, respectively. The combination of a mechanically resistant frustule with high aspect ratio and rib-slit structure contributes to their mechanical robustness compared to the Coscinodiscus sp. frustules.

3D CAD models were successfully applied to simulate the experimental mechanical response

of diatom frustules, and can be used to design diatom-inspired structures. FEM simulations of validated 3D diatom models highlighted details on the effect of a uniform load on the diatom frustule. Simulations showed that the frustules investigated differed in their mechanical behavior under uniform compression conditions, relevant for nanotemplate applications. For centric Coscinodiscus $s p$. frustules, centralized (and decreasing radially outward) compressive strains 
and modest von Mises stress distributions were predicted. Increasing the pore size in this frustule may effectively lead to an improved (flexible) porous structure, undergoing homogeneous lower stress levels in critical areas such as pores and frustule sides. For pennate Synedra sp. frustules, compression resulted in uniform elevated strains and von Mises stress distributions in comparison to centric diatoms. Decreasing the slit width size in this frustule resulted in another enhanced structure, one which can sustain lower stress distributions around critical areas such as frustule edges. These unique mechanical responses will in turn define the applications that a future similar nanostructured material will be best suited for. The approach of coupling experimental and simulation methods allowed the analysis of the mechanical properties of another pennate (F. kerguelensis) frustule with characteristic pores, instead of slits. Increasing the pore size in simulations led to rigid frustule structure with a significantly lower ability to bend while maintaining a similar stress distribution, compared to the equivalent diatom in nature. More experiments are needed to more precisely predict the mechanical properties of this frustule.

The implications of the relationships between mechanical properties vs. porosity examined in this study for the selected frustules are multi-fold. These include the ability to identify superior deformability (or stress-resistance) of similar diatom-inspired structures, investigate the role of the layered structure in a diatom frustule, incorporate advanced structural mechanical analysis for the study of hierarchical layers, design tailored properties for desired geometries, and map strategies for the fabrication of nanostructures and nanodevices. Future experiments (e.g., etching) and simulation efforts (e.g., to examine the role of porosity on von Mises stress) will need to include investigation of diatom species-specific Young's moduli and complete diatom frustule morphology as design criteria for optimizing future material performance. 
Nanomechanical testing and simulation-based prediction of displacement and von Mises stress distributions in diatom frustules can help direct fabrication efforts (e.g., by guiding the amount and location of nanomaterials to be deposited on porous nanotemplates). Applications subject to significant stress, such as in drug delivery of nanomaterials, might be feasible with a structure similar to the pennate diatom ( $F$. kerguelensis). Most significantly, the results presented here could be applied to nanoparticle-encapsulated diatoms to deliver therapeutics, similar to those recently investigated by Todd et al. [30]. This study is significant toward understanding hierarchical porous structures and developing advanced materials for a wide range of applications via controlled morphologies and structures. Further progress in materials innovation, testing methods and additive manufacturing will also be needed to fully characterize the effects of microstructure on associated properties, and to design for performance across many length scales. Recent diatom research [31-32] indicates that studies such as the present work are necessary for the fabrication of prototypes of diatom-inspired structures with desired properties.

\section{ACKNOWLEDGEMENTS}

The authors would like to thank T. Ye and G. Abel (University of California, Merced) and J. Dunec (COMSOL) for helpful discussions, G. Gage (University of Michigan) for facilitating materials for fabricating the micromanipulator, and T. Allis (University of California, Merced) for technical assistance. This work was performed under the auspices of the NSF-funded COINS award under contract EEC-0832819. A Miguel Velez and GRC scholarships supported co-author (MDM), with conference funds. The AFM at the University of California, Merced is supported by an NSF CRIF award (CHE 1048651). Funding for the nanoindentation experiments and facilities at the University of California, Davis were provided by the Office of Naval Research (Contract N00014-12-C-0241) and the National Science Foundation (Grant DMR-9803045). 


\section{REFERENCES}

1. Fleming GR, Ratner MA. Grand challenges in basic energy sciences. Phys Today 2008; 61: 28-33.

2. NSF: Design materials to revolutionize and engineer our future. Website last accessed: January 15, 2015 from http://www.nsf.gov/pubs/2011/nsf11089/nsf11089.jsp

3. Aizenberg J, Weaver JC, Thanawala MS, Sundar VC, Morse DE, Fratzl P. Skeleton of euplectella sp.: structural hierarchy from the nanoscale to the macroscale. Science 2005; 309 : 275-278.

4. MRS Communications unveils unique new prospect for materials research. Website last accessed: January 20, 2015 from http://www.mrs.org/pr-05-02-2012/

5. Hildebrand M. Diatoms, biomineralization processes, and genomics. Chem Rev 2008; 108: 4855-4874.

6. Hamm CE, Merkel R, Springer O, Jurkojc P, Maier C, Prechtel K, Smetacek V. Architecture and material properties of diatom shells provide effective mechanical protection. Nature 2003; 421: 841-843.

7. Kröger N, Brunner E. Complex-shaped microbial biomaterials for nanotechnology. WIRES Nanomed Nanobiotechnol 2014; 6: 615-627.

8. Kröger N, Poulsen N. Diatoms-from cell wall biogenesis to nanotechnology. Annu Rev Genet 2008; 42: 83-107.

9. Viji et al. Diatom-based label-free optical biosensor for biomolecules. Appl Biochem Biotechnol 2014; 174: 1166-73.

10. Toster J, Iyer KS, Xiang W, Rosei F, Spiccia L, Raston CL. Diatom frustules as light traps enhance DSSC efficiency. Nanoscale 2013; 5: 873-876.

11. Gordon R, Sterrenburg F, Sandhage K. A Special Issue on Diatom Nanotechnology. J Nanosci Nanotechnol 2005; 5: 1-178.

12. Gordon R, Losic D, Tiffany MA, Nagy SS, Sterrenburg FAS. The glass menagerie: diatoms for novel applications in nanotechnology. Trends Biotechnol 2009; 27: 116-127; Neethirajan S, Gordon R, Wang L. Potential of silica bodies for nanotechnology. This issue 2009; 27: 462-467.

13. Pérez-Cabero M, Puchol V, Beltrán D, Amorós P. Thalassiosira pseudonana diatom as biotemplate to produce a macroporous ordered carbon-rich material, Carbon 2008; 46: 297-304.

14. Gutu T, Jeffryes C, Wang W, Chang CH, Rorrer GL, Jiao J. Structural and electrical characterization of diatom Pinnularia sp. biosilica coated with CdS thin film. Mater Res Soc Symp Proc 2009; 1187: 1187-KK05-20.

15. Raven JA, Waite AM. The evolution of silicification in diatoms: inescapable sinking and sinking as escape? New Phytol 2004; 162: 45-61.

16. Higgins MJ, Crawford SA, Mulvaney P, Wetherbee R. Characterization of the adhesive mucilages secreted by live diatom cells using atomic force microscopy. Protist 2002; 153: 25-38. 
17. Higgins MJ, Sader JE, Mulvaney P, Wetherbee R. Probing the surface of living diatoms with atomic force microscopy: the nanostructure and nanomechanical properties of the mucilage layer. J Phycol 2003; 39: 722-734.

18. Losic D, Short K, Mitchell JG, Lal R, Voelcker NH. AFM nanoindentations of diatom biosilica surfaces. Langmuir 2007; 23: 5014-5021.

19. Losic D, Pillar R, Dilger T, Mitchell J, Voelcker N. Atomic force microscopy (AFM) characterisation of the porous silica nanostructure of two centric diatoms. J Porous Mat 2007; 14 : 61-69; Losic D, Rosengarten G, Mitchell JG, Voelcker NH. Pore architecture of diatom frustules: potential nanostructured membranes for molecular and particle separations. J. Nanosci Nanotechnol 2006; 6: 1-8.

20. Hildebrand M, Doktycz M, Allison D. Application of AFM in understanding biomineral formation in diatoms. Pflügers Archi EJP 2008; 456: 127-137.

21. Yao S, Subhash G, Maiti S. Analysis of nanoindentation response of diatom frustules. J Nanosci Nanotechnol 2007; 7: 4465-4472; Subhash G, Yao S, Bellinger B, Gretz MR. Investigation of mechanical properties of diatom frustules using nanoindentation. $\mathrm{J}$ Nanosci Nanotechnol 2005; 5: 50-56.

22. Garcia A, Sen D, Buehler M. Hierarchical silica nanostructures inspired by diatom algae yield superior deformability, toughness, and strength. Metall Mater Trans A 2011; 42: 1-9.

23. Bao et al. Chemical reduction of three-dimensional silica micro-assemblies into microporous silicon replicas. Nature 2007; 446: 172-175.

24. Hasle GR, Fryxell GA. Diatoms: cleaning and mounting for light and electron microscopy. T Am Microsc Soc 1970; 89: 469-474.

25. Oliver WC, Pharr GM. An improved technique for determining hardness and elastic modulus using load and displacement sensing indentation experiments. J Mater Res 1992; 7: 1564-1583.

26. Shuman DJ, Costa ALM, Andrade MS. Calculating the elastic modulus from nanoindentation and microindentation reload curves. Mat Charac 2007; 58: 380-389.

27. Almqvist et al. Micromechanical and structural properties of a pennate diatom investigated by atomic force microscopy. J Microsc 2001; 202: 528-532.

28. Structural Mechanics User's Guide. Comsol Multiphysics. COMSOL, Palo Alto, California, 2013.

29. Bower A.F. Applied mechanics of solids. CRC/Taylor \& Francis. Boca Raton, Florida: 2010. p 47-49.

30. Todd et al. Iron oxide nanoparticle encapsulated diatoms for magnetic delivery of small molecules to tumors. Nanoscale 2014; 6: 2073-2076.

31. Jang D, Meza LR, Greer F, Greer JR. Fabrication and deformation of three-dimensional hollow ceramic nanostructures. Nature Mater 2013; 12: 893-898.

32. Belegratis MR, Schmidt V, Nees D, Stadlober B, Hartmann P. Diatom-inspired templates for 3D replication: natural diatoms vs. laser written artificial diatoms. Bioinspir Biomim 2014; 9: 0160041-11. 

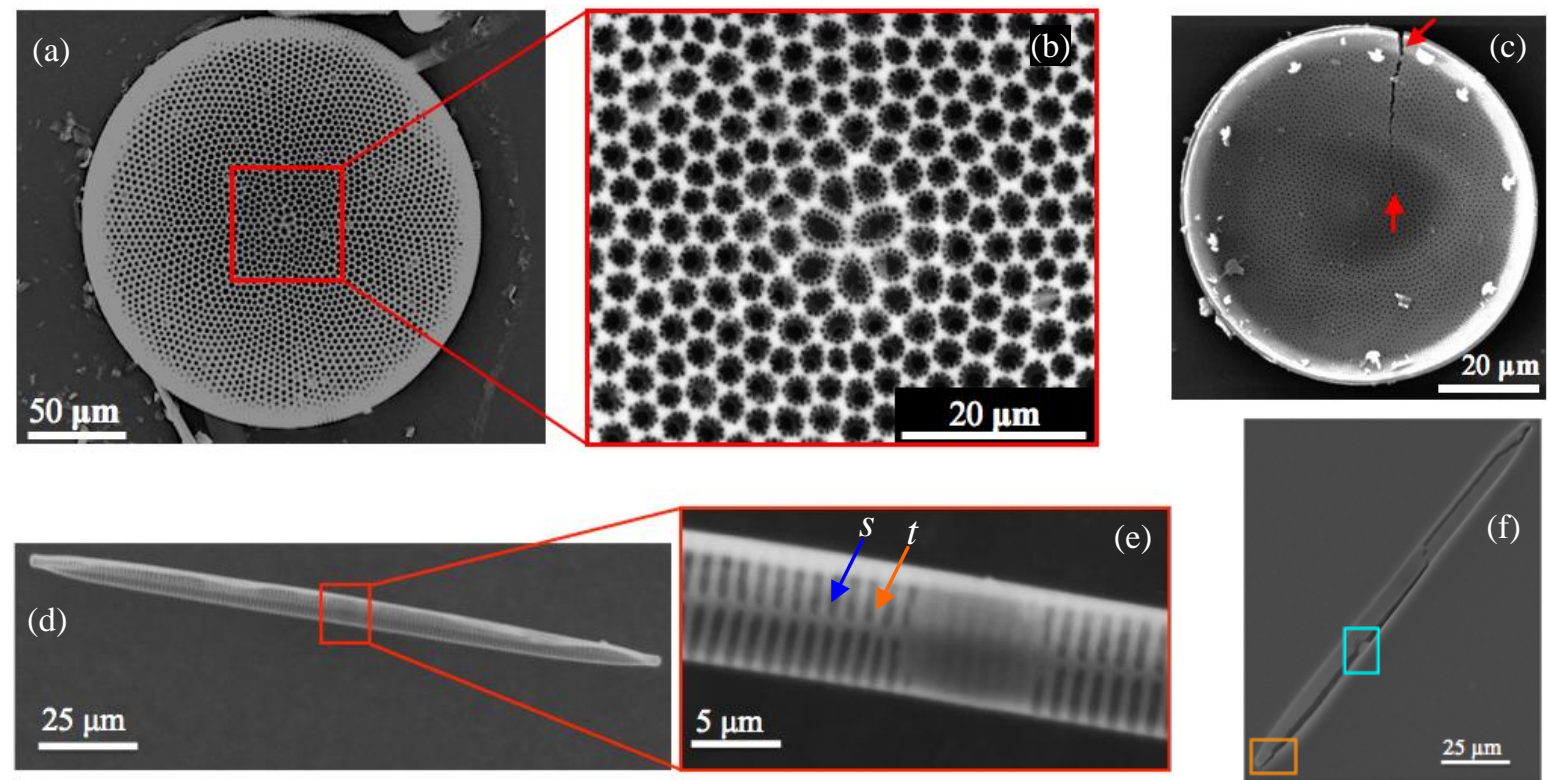

Fig. 1. (Color online/print) SEM micrograph of a characteristic Coscinodiscus sp. diatom frustule (a-b) and a Synedra sp. diatom frustule (d-e) examined prior to nanoindentation experiments. The biosilica centric frustule (a) has a diameter $\sim 200 \mu \mathrm{m}$ and a highly ordered pore arrangement $(\mathrm{b})$, which varies in size $(d \sim 4.8 \mathrm{~nm})$ and orientation. The pennate frustule (d) has a length $l$ of $\sim 160 \mu \mathrm{m}$, a width $w$ of $\sim 7 \mu \mathrm{m}$, and contains valve surfaces with distinct features such as lateral longitudinal structures (e) with a thin slit width $s$ of $\sim 0.4 \mu \mathrm{m}$ (blue arrow) and a rib thickness $t$ of $\sim 0.5 \mu \mathrm{m}$ (orange arrow). Representative SEM images of these diatom frustules reveal distinct types of indent marks after nanoindentation tests. Centric frustule image (c) shows surface pits and an extended crack shown via red arrows. Pennate diatom image (f) depicts a longitudinal crack, which reaches one end of the frustule after nanoindentation. 

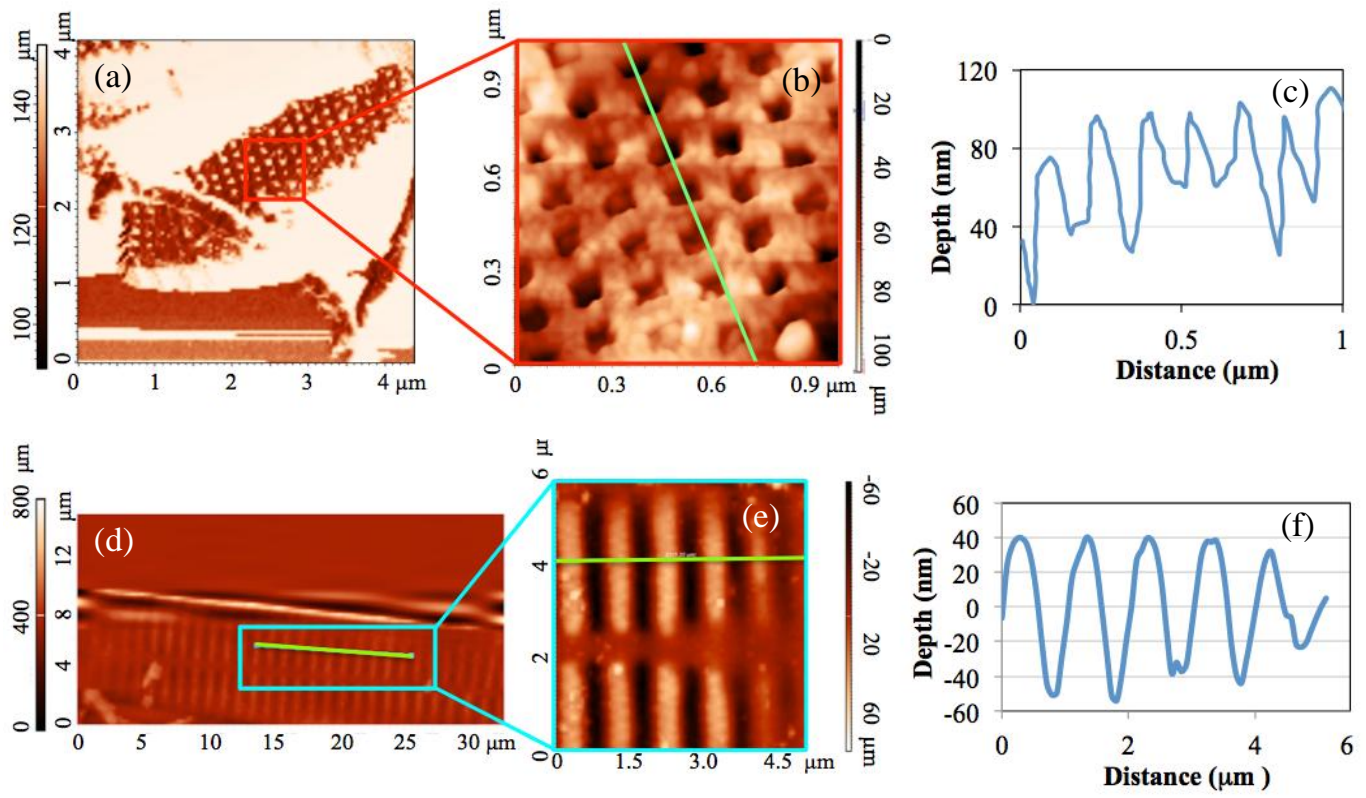

Fig. 2. (Color online/print) AFM image of a centric Coscinodiscus sp. diatom frustule (a-c) displaying its ordered mesh-like porous structure (a) and a hierarchical layered structure (b), and its corresponding depth-distance profile (measured along a line shown in green) from the layer of the frustule (c), revealing a regular pore pattern. The pennate Synedra sp. diatom frustule (d-f) shows its elongated structure (d) with characteristic ribs and slits (e), and its related depth-distance profile (measured along its corresponding green line) from the top layer of the frustule (f), displaying an ordered slit pattern. 

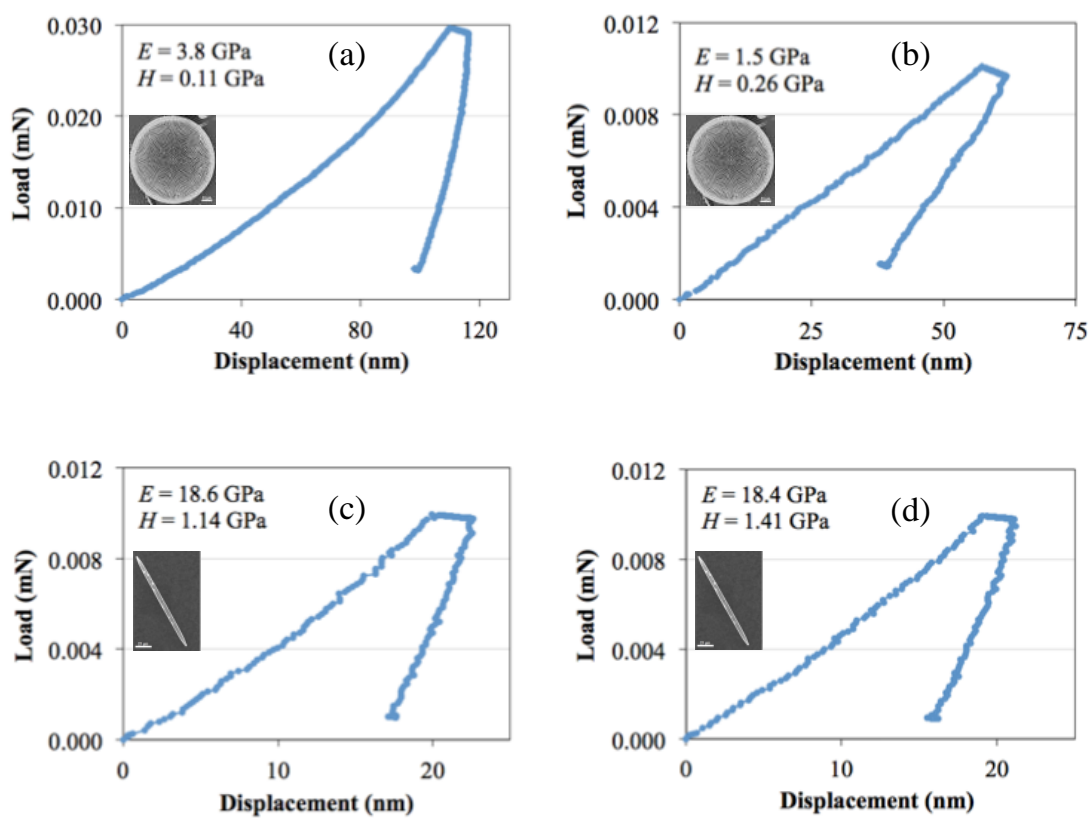

Fig. 3. (Color online/print) Ambient nanoindentation curves: characteristic experimental determinations of Young's moduli for Coscinodiscus sp. diatom frustules (a-b) show that values are low (average $E=3.1 \mathrm{GPa}$ ) compared to the value for bulk silica glass $(73 \mathrm{GPa})$. Additional nanoindentation curves: representative experimental measurements of Young's moduli for Synedra sp. diatom frustules (c-d) show that values are significantly higher (average $E=16.6$ $\mathrm{GPa}$ ) compared to the Coscinodiscus sp. diatom frustules. Nanoindentation was applied to the top frustule surfaces. 


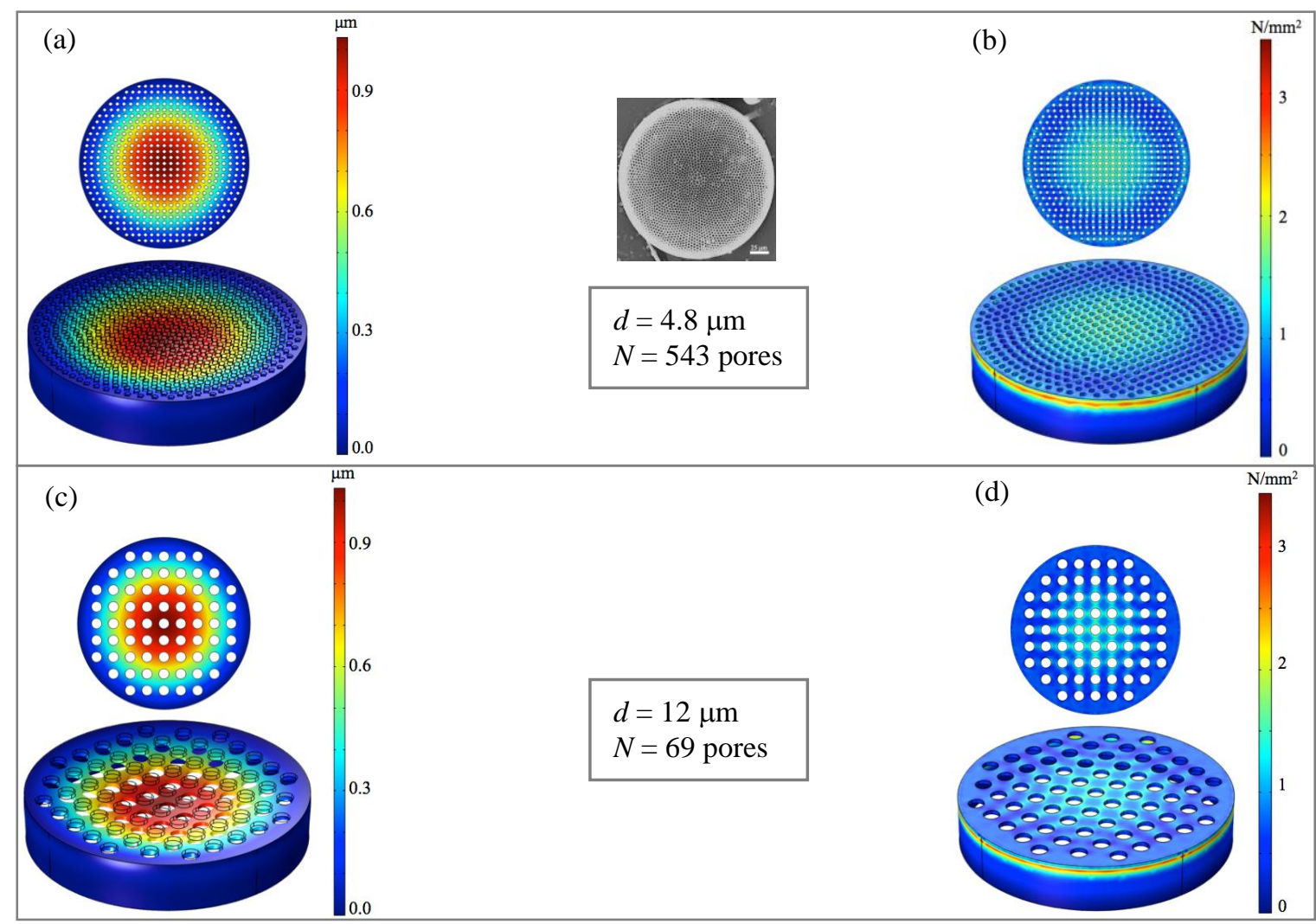

Fig. 4. (Color online/print) FEM uniform elastic compression simulation of Coscinodiscus sp. diatoms (epitheca only, $D=200 \mu \mathrm{m}$ ). Top figures show displacement (a) and stress distributions (b) for models similar to those found in nature $(d=4.8 \mu \mathrm{m})$. Bottom figures (c)-(d) show equivalent results when $d$ is increased, relevant for microtemplate applications $(d=12 \mu \mathrm{m})$. Views above each 3D model show features of each distribution without displacement. Dimensions of the "modified" diatom frustule models and calculated mechanical properties are included in Table 3. 


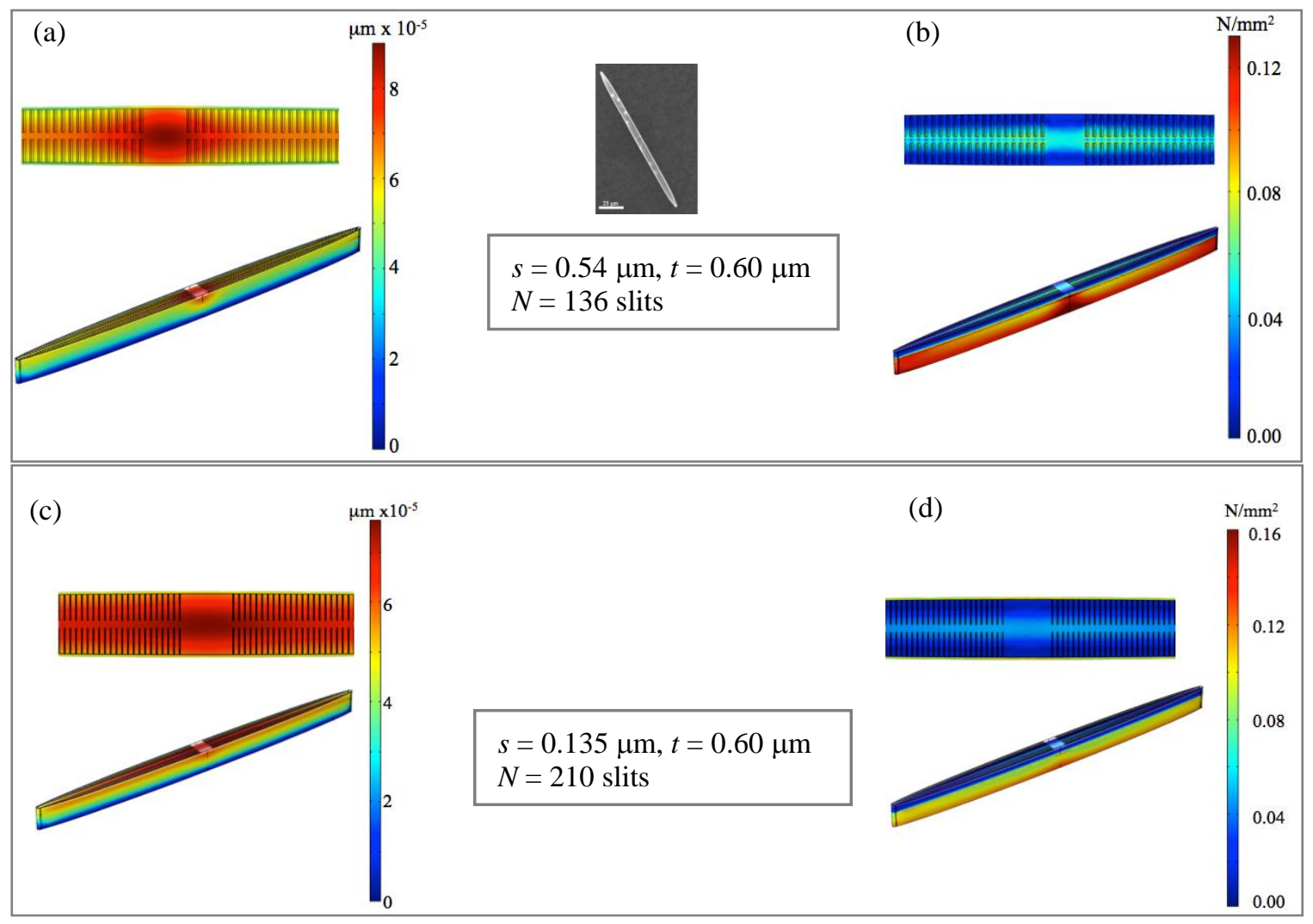

Fig. 5. (Color online/print) FEM uniform elastic compression simulation of Synedra sp. diatom frustules (epitheca only, length $l=162 \mu \mathrm{m}$, width $w=8 \mu \mathrm{m}$, and rib thickness $t=0.60 \mu \mathrm{m}$ ) shows displacement (a) and stress distributions (b) of the top surface for frustules typically found in nature (slit width $s=0.54 \mu \mathrm{m}$ ). Figures (c)-(d) show the effect of decreasing this dimension $(s=0.135 \mu \mathrm{m})$, keeping $t=0.60 \mu \mathrm{m}$ constant, thus increasing the number of slits and ribs. Close-up views above each 3D model show each distribution without displacement. Table 3 depicts relevant data. 


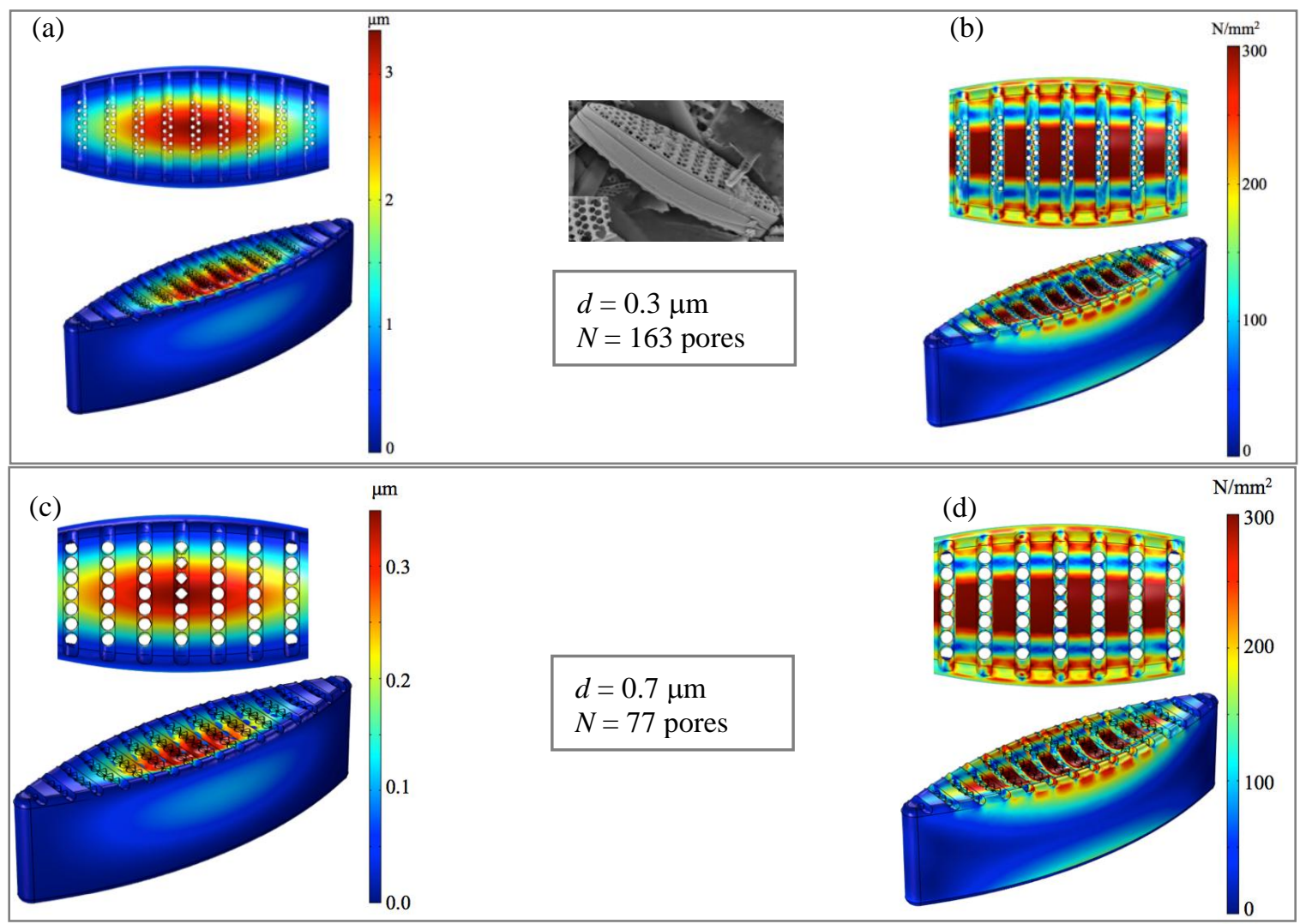

Fig. 6. (Color online/print) FEM uniform elastic compression simulation of pennate (F. kerguelensis) diatom frustules (epitheca only, frustule length $l=30 \mu \mathrm{m}$, and frustule width $w=7.83 \mu \mathrm{m}$ ). Top figures show displacement (a) and stress distributions (b) for models with dimensions and pore sizes as in nature $(d=0.3 \mu \mathrm{m})$. Bottom figures (c)(d) reveal differences for the "modified" frustules when pore size is increased $(d=0.7 \mu \mathrm{m})$. As before, close-up views of each distribution without displacement are shown and dimensions of the "modified" frustules and properties are found in Table 3 . 

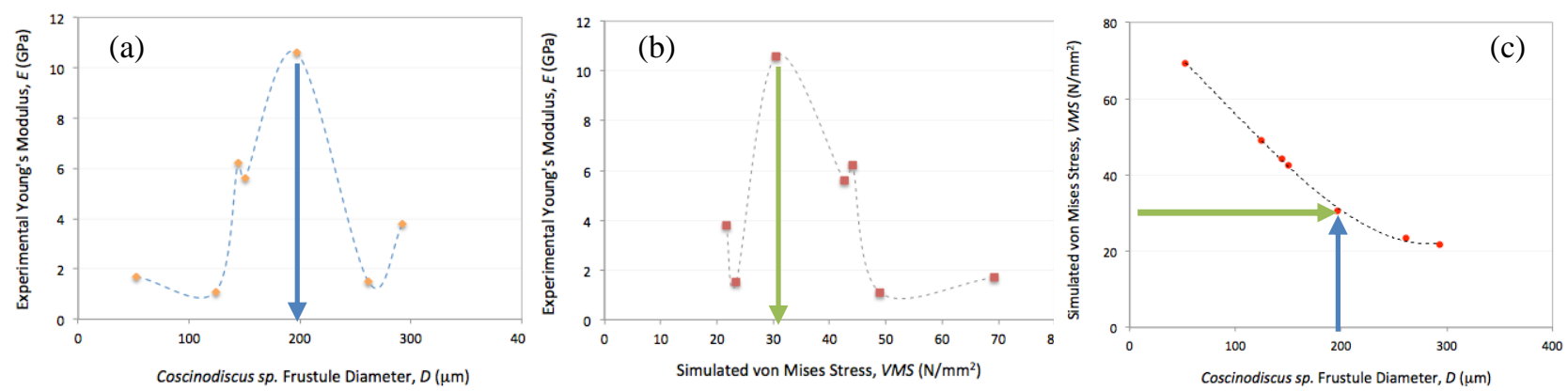

Fig. 7. (Color online/print) Correlations observed in this study in the behavior of centric Coscinodiscus sp. frustule in experiments and compression simulations: (a) frustule diameter $D$ vs. experimental Young's modulus $E$, (b) maximum von Mises stress vs. experimental Young's modulus $E$, and (c) frustule diameter $D$ vs. maximum von Mises stress. Guidelines denote traits $\left(D \sim 200 \mu \mathrm{m}, E \sim 11 \mathrm{GPa}\right.$, von Mises stress $\sim 30 \mathrm{~N} / \mathrm{mm}^{2}$ ) for an optimal Coscinodiscus sp. diatom frustule. 

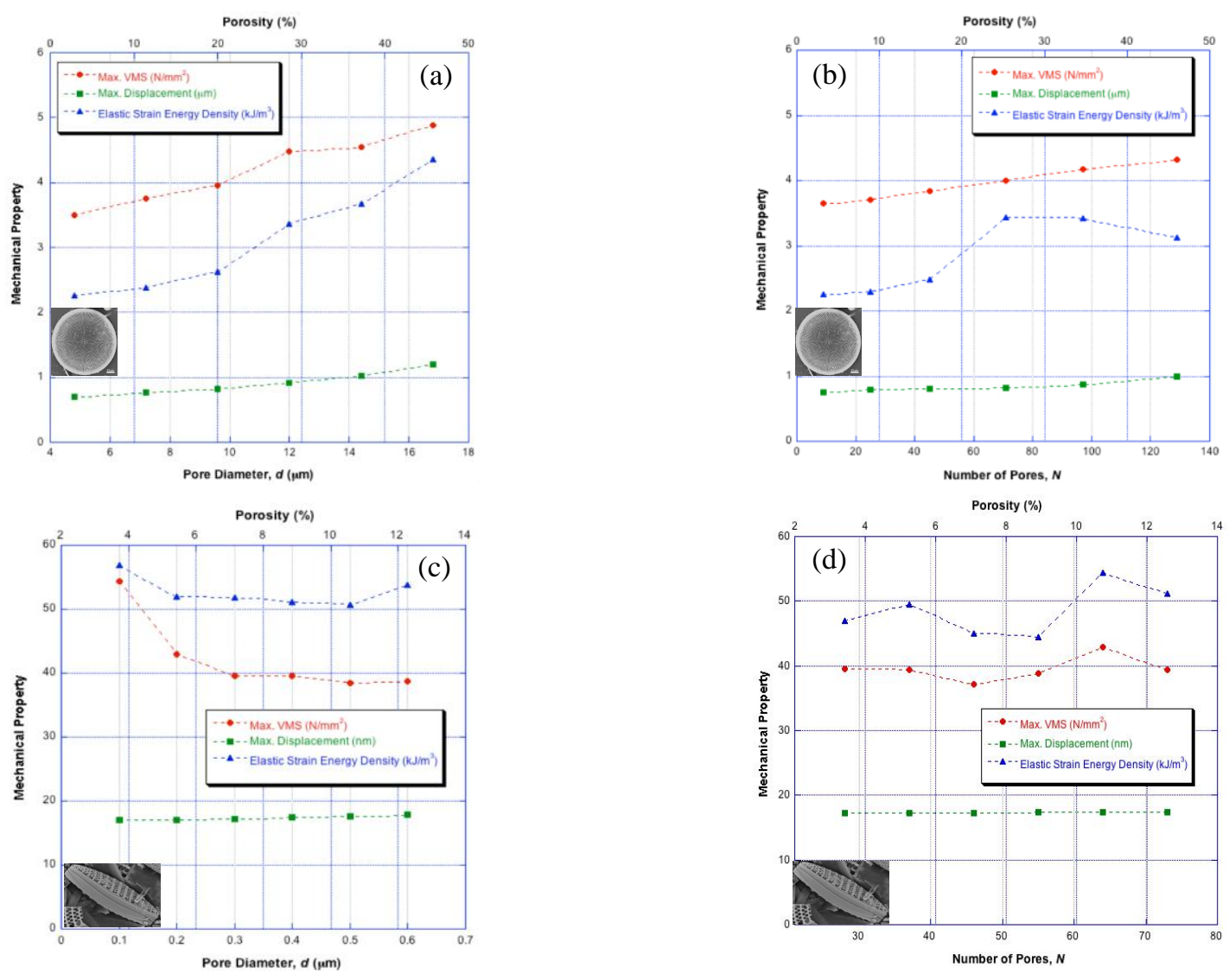

Fig. 8. (Color online/print) Effect of (a) pore diameter and (b) number of pores on selected mechanical properties upon FEM uniform elastic compression simulations for centric Coscinodiscus sp. diatom models. Similar analysis of the role of (c) pore diameter and (d) number of pores on mechanical properties for pennate F. kerguelensis diatom models is included. 
